Sādhanā Vol. 28, Part 5, October 2003, pp. 957-974. (C Printed in India

\title{
Nano finish grinding of brittle materials using electrolytic in-process dressing (ELID) technique
}

\author{
M RAHMAN, A SENTHIL KUMAR, H S LIM and K FATIMA \\ Department of Mechanical Engineering, National University of Singapore, \\ Singapore 119260 \\ e-mail: mpemusta@nus.edu.sg
}

\begin{abstract}
Recent developments in grinding have opened up new avenues for finishing of hard and brittle materials with nano-surface finish, high tolerance and accuracy. Grinding with superabrasive wheels is an excellent way to produce ultraprecision surface finish. However, superabrasive diamond grits need higher bonding strength while grinding, which metal-bonded grinding wheels can offer. Truing and dressing of the wheels are major problems and they tend to glaze because of wheel loading. When grinding with superabrasive wheels, wheel loading can be avoided by dressing periodically to obtain continuous grinding. Electrolytic inprocess dressing (ELID) is the most suitable process for dressing metal-bonded grinding wheels during the grinding process. Nano-surface finish can be achieved only when chip removal is done at the atomic level. Recent developments of ductile mode machining of hard and brittle materials show that plastically deformed chip removal minimizes the subsurface damage of the workpiece. When chip deformation takes place in the ductile regime, a defect-free nano-surface is possible and it completely eliminates the polishing process. ELID is one of the processes used for atomic level metal removal and nano-surface finish. However, no proper and detailed studies have been carried out to clarify the fundamental characteristics for making this process a robust one. Consequently, an attempt has been made in this study to understand the fundamental characteristics of ELID grinding and their influence on surface finish.
\end{abstract}

Keywords. Nano-grinding; ELID; superabrasive grinding wheels; ductile regime.

\section{Introduction}

Demand for better surface finish and accuracy has been increasing rapidly in recent years. Nano-surface finish has become an important parameter in the semiconductor, optical, electrical and mechanical industries. The materials used in these industries are classified as difficult to machine materials such as ceramics, glasses and silicon wafers. Machining of these materials up to nano accuracy is a great challenge in the manufacturing industry. Finishing of micro components such as micro-moulds, micro-lenses and micro-holes need different processing techniques. Conventional finishing methods used so far become almost impossible or cumbersome. 
Grinding is one of the versatile finishing techniques that can be used to produce surface finish up to the micrometric level. Then the final surface finish at sub-micron level can be achieved by using lapping or polishing processes. The major disadvantages of the above processes are the lack of tolerance and accuracy. For example, nano-surface finish is an essential factor in printing fine wiring circuits using lithography technique. The surface finish of wafers polished using CMP was found with some surface irregularities like step differences.

To obtain mirror surface finish, chip removal from the material surfaces should be minimized. Nano-surface finish of brittle materials is possible when the chip size reaches atomic level. Finishing with superabrasive diamond grits is the apt method to achieve this. But, superabrasive grits need higher bonding strength for better efficiency. Metal-bonded diamond superabrasive grinding wheels have higher bonding strength and high stability. The major problems encountered using superabrasive wheels during grinding are loading and glazing. In order to avoid these difficulties, the wheel should be dressed periodically, which makes the grinding process very tedious.

Electrolytic in-process dressing (ELID) is an efficient method that eliminates wheel loading and glazing problems. The wheel is dressed using electrolysis during grinding, which helps to maintain larger grain protrusions and grit density. ELID is a simple and efficient technique that can be adopted for any conventional grinding machines. In this paper, authors attempt to explain the principle, techniques, applications and recent developments in nano-grinding using ELID (Ohmori \& Nakagawa 1990).

\section{Development and mechanism of ELID grinding}

Murata et al (1985) introduced ELID for the application of abrasive cut-off of ceramics. Structural ceramics are highly difficult to grind due to their hard and brittle nature. Normally, for grinding harder materials, softer grade grinding wheels have been used. However softer grinding wheels have the problem of large diameter decrease due to wheel wear. Therefore, stronger bonds with harder abrasives have been selected for grinding hard and brittle materials.

Figure 1 shows the schematic illustration of ELID. When the grits are worn out, a new layer in the outer surface is electrolysed and necessary bonding material is removed from the grinding wheel surface in order to realise grit protrusion. The experiments were performed using metal-bonded grinding wheels (not specified) of grit size \#80, \#100, \#150 and \#400.

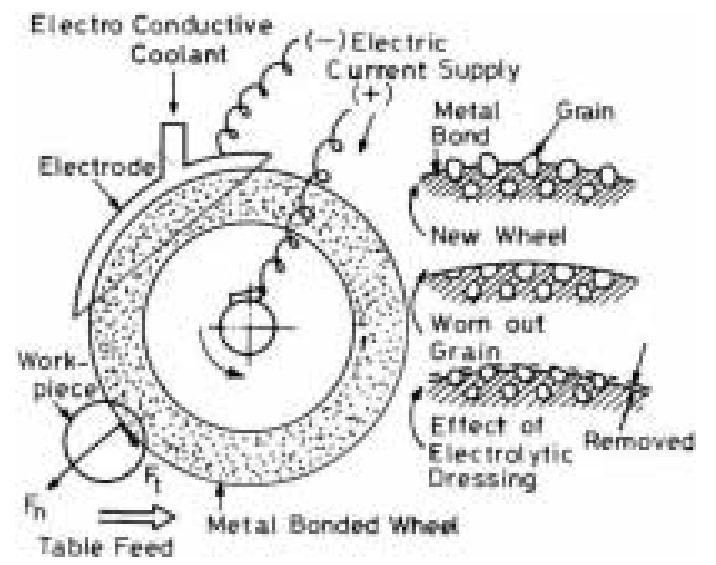

Figure 1. Schematic illustration of ELID (Murata et al 1985). 


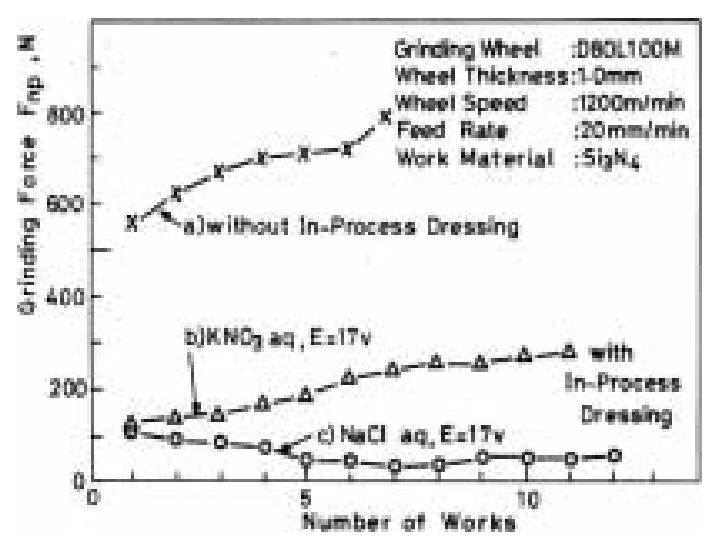

Figure 2. Comparison of grinding forces during ELID and without ELID (Murata et al 1985).

The results showed that the grinding force was reduced to a significant amount when the inprocess dressing was done. Even though the surface finish is not a major criterion in abrasive cut-off, the surface roughness also improved due to the application of ELID. Figure 2 shows a comparison of the grinding forces using ELID and conventional grinding respectively. From the experiments it was concluded that ELID is an effective process of increasing surface quality even though it has some problems like rust formation due to electrolyte application (Murata et al 1985).

Ohmori et al $(1990,1999)$ further improved ELID to be suitable for superabrasive grinding wheels. Different types of grinding wheels have been used along with ELID grinding (Ohmori \& Nakagawa 1995). The grinding wheels used in ELID are broadly classified into the following:

- Metal-bonded diamond grinding wheels and

- Metal-resin-bonded diamond grinding wheels.

Normally cast iron or copper is used as the bonding material. Some amount of cobalt can also be included in the bonding material for better grinding performance. Metal and resin are mixed in a definite ratio in order to get good grinding performance. Normally copper is used as bonding material for metal-resin bonded grinding wheels. The grades of the grinding wheels range from \#325 to \#30,000, which has an average grit size from $38 \mu \mathrm{m}$ to $0.5 \mathrm{~nm}$.

The power supply for ELID is used to control the dressing current, voltage and pulse width of the dressing process. The basic ELID system consists of a metal-bonded diamond grinding wheel, an electrode, a power supply and an electrolyte as shown in figure 3 . The

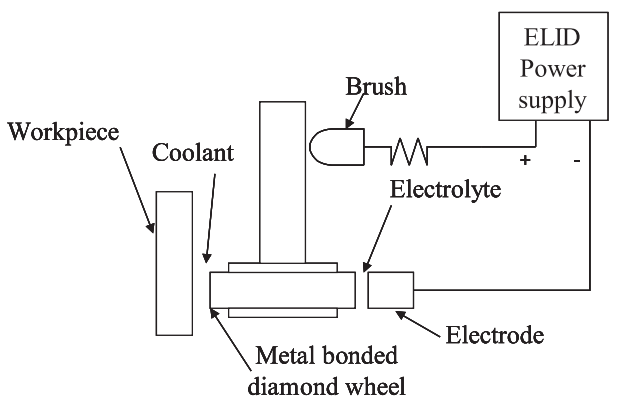

Figure 3. Principle of ELID. 
metal-bonded grinding wheel is made the positive pole through the application of a brush smoothly contacting the wheel shaft and the electrode is made negative pole. In the small clearance between the positive and negative poles, electrolysis occurs through the supply of the grinding fluid and an electrical current.

\section{Different methods of ELID grinding}

ELID is classified into four major groups based on the materials to be ground and the applications of grinding, even though the principle of in-process dressing is similar for all the methods. The different methods are as follows.

(1) Electrolytic in-process dressing (ELID-I)

(2) Electrolytic interval dressing (ELID-II)

(3) Electrolytic electrode-less dressing (ELID-III), and

(4) Electrolytic electrode-less dressing using alternate current (ELID-IIIA).

\subsection{Electrolytic in-process dressing (ELID-I)}

As explained before, basic ELID system consists of an ELID power supply, a metal-bonded grinding wheel and an electrode. The electrode used could be $1 / 4$ or $1 / 6$ of the perimeter of the grinding wheel. Normally copper or graphite is selected as the electrode material. The gap between the electrode and the grinding wheel is adjusted up to 0.1 to $0.3 \mathrm{~mm}$. Proper gap and coolant flow rate should be selected for efficient in-process dressing. Normally arc-shaped electrodes are used in this type of ELID and the wheel used is either straight or cup type.

Figure 4 shows the mechanism of ELID grinding of metal-bonded diamond wheel. After truing (a), the grains and bonding material of the wheel surface are flattened. It is necessary for the trued wheel to be electrically pre-dressed to protrude the grains on the wheel surface. When pre-dressing starts (b), the bonding material flows out from the grinding wheel and an insulating layer composed of the oxidized bonding material is formed on the wheel surface (c). This insulating layer reduces the electrical conductivity of the wheel surface and prevents excessive flow out of the bonding material from the wheel. As grinding begins (d), diamond grains wear out and the layer also becomes worn out (e). As a result, the electrical conductivity of the wheel surface increases and the electrolytic dressing restarts with the flow out of bonding material from grinding wheel. The protrusion of diamond grains from the

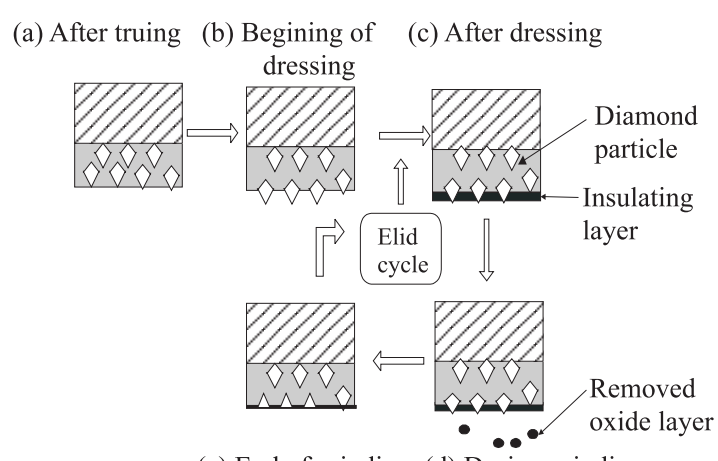

(e) End of grinding (d) During grinding
Figure 4. Mechanism of ELID grinding. 
grinding wheel therefore remains constant. This cycle is repeated during the grinding process to achieve stable grinding (Ohmori \& Nakagawa 1995; Bi Zhang et al 2000; Fujihara et al 1997; Bandyopadhyay et al 1996).

\subsection{Electrolytic interval dressing (ELID-II)}

Small hole machining of hard and brittle materials is highly demanded in most of the industrial fields. The problems in micro hole machining include the following.

- Difficulty in preparing small grinding wheels of high quality

- Calculating grinding wheel wear compensation

- Accuracy and surface finish of holes not being satisfactory.

The existing ELID grinding process is not suitable for micro-hole machining because of the difficulty in mounting of electrodes. Using the combination of sintered metal-bonded grinding wheels of small diameter, Electric Discharge Truing (EDT) and Electrolytic Interval Dressing (ELID-II) could solve the problems in micro-hole machining. The smallest grinding wheel, for example of diameter $0.1 \mathrm{~mm}$ can also be trued accurately by using EDT method, which uses DC-RC electric power. The small grinding wheels can be pre-dressed using electrolysis in order to gain better grain protrusions. The dressing parameters should be selected carefully to avoid excessive wear of grinding wheel. The grinding wheel is dressed at definite intervals based on the grinding force. If the grinding force increases beyond a certain threshold value, the wheel is re-dressed. Figure 5 shows the novel method of micro-hole machining using ELID -II (Ohmori \& Nakagawa 1995; Qian et al 2001; Zhang et al 2000).

(a)
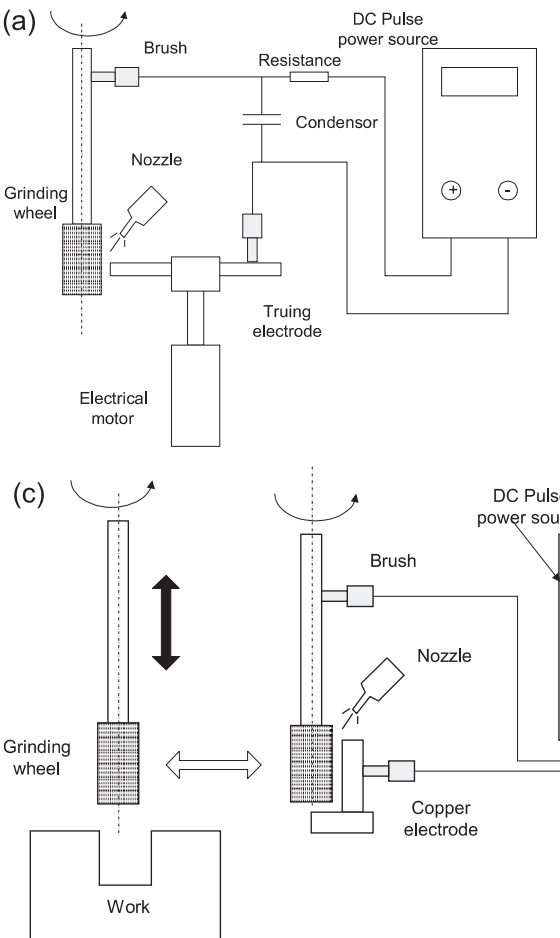
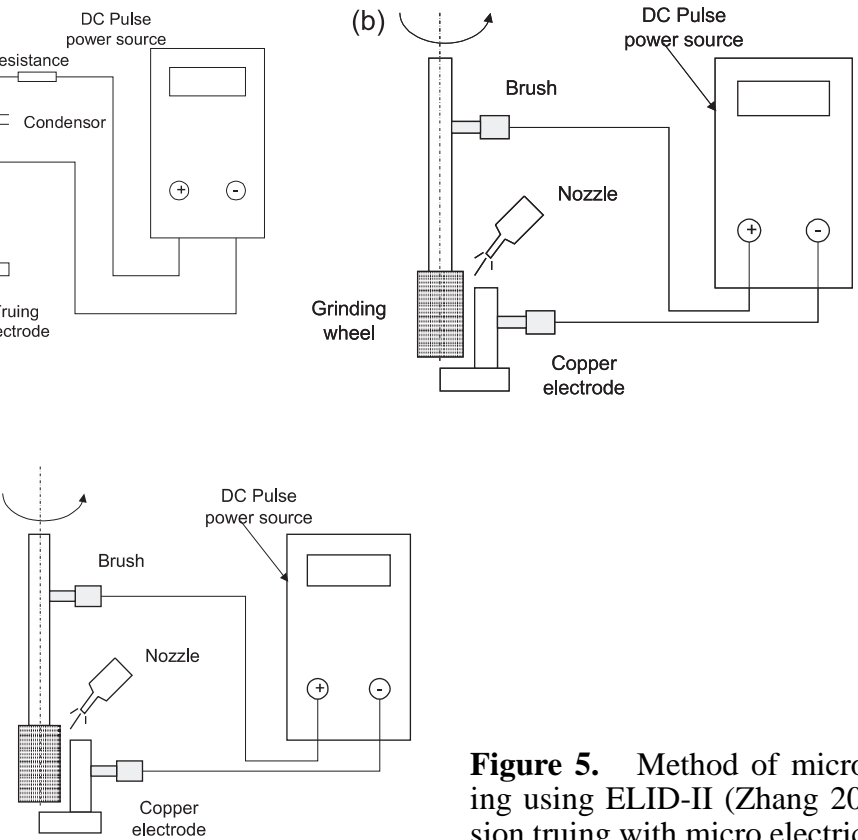

Figure 5. Method of micro-hole machining using ELID-II (Zhang 2000). (a) Precision truing with micro electric discharge truing method. (b) Pre-dressing with nonlinear electrolytic process (c) Dynamic grinding of small hole using ELID-II. 


\subsection{Electrode-less in-process dressing (ELID-III)}

Grinding of materials such as steel increases the wheel loading and clogging due to embedding of swarf on the grinding wheel surface and thus reduces the wheel effectiveness. If the size of swarf removal is smaller, the effectiveness of the grinding wheel increases. For machining conductive materials like hardened steels, metal-resin-bonded grinding wheels have been used. The conductive workpiece acts as the electrode and the electrolysis occurs between the grinding wheel and the workpiece. Normally the bonding material used for grinding wheels is copper or bronze. The electrolytic layer is formed on the workpiece and is removed by the diamond grits. Thus swarf production is controlled by using electrodeless in-process dressing (ELID-III). During electrolytic dressing, the base material is oxidized and the wheel surface contains resin and diamond grits. Theoretically the metal-bond is removed by electrolysis, but the experimental results showed that the grinding wheel surface contains cavities, which are caused by electric discharge. When high electric parameters are chosen, the amount of electric discharge increases and causes damage on both the wheel and ground surfaces. For better surface finish, low voltage, low current, low duty ratio and low in-feed rate should be selected. Figure 6 shows the schematic illustration of ELID-III (Ohmori 2000).

\subsection{Electrode-less in-process dressing using alternative current (ELID-IIIA)}

The difficulties of using electrode-less in-process dressing could be eliminated with the application of ELID-IIIA. Figure 7 shows the ELID-IIIA principle, and the difference between ELID-III and ELID-IIIA. The alternative current produces a thick oxide layer film on the

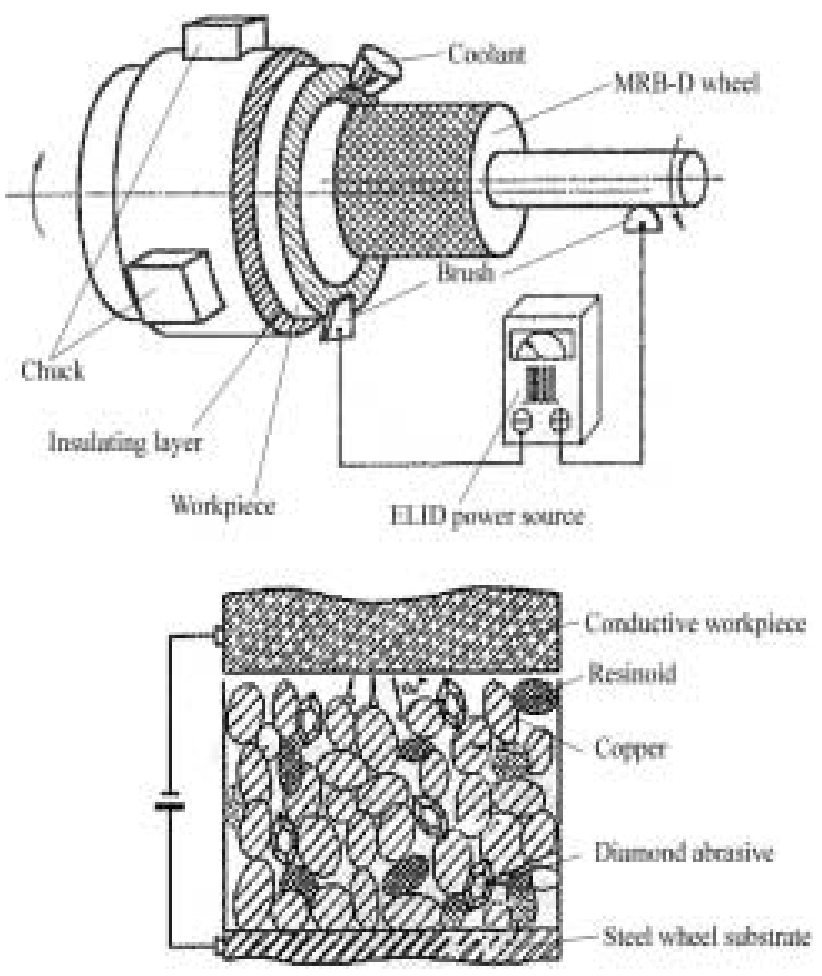

Figure 6. Principles of electrodeless dressing (ELID-III) (Ohmori 2000). 

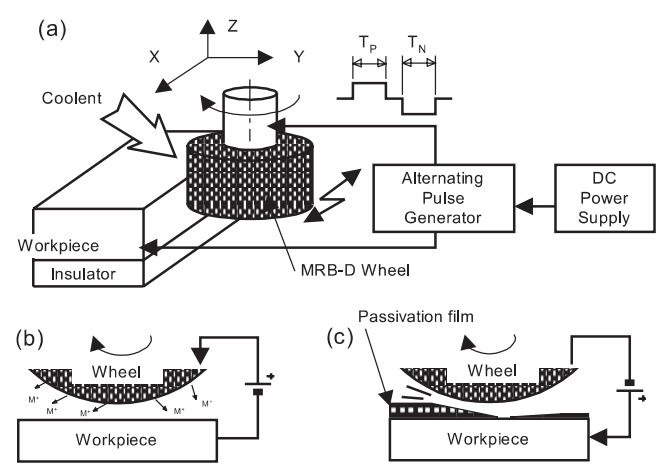

Figure 7. Schematic diagram of ELID-IIIA (Lim et al 2000, 2001) (a) ELID-3 machining system with alternating cuttent. (b) ELID without electrode. (c) Electrolysis of workpiece.

surface of the workpiece, which prevents direct contact between the grinding wheel and the workpiece. Thus the electric discharge between the wheel and workpiece is completely eliminated and the ground surface finish is improved (Lim et al 2000, 2001).

\section{Applications of ELID grinding process}

This section explains the applications of the ELID for different difficult to grind materials used for various applications.

\subsection{Structural ceramic components}

Structural ceramic has been used widely because of its excellent properties such as high wear resistance, high thermal resistance and high resistance to chemical degradations. Cutting tools, automobile parts and aerospace turbochargers are the most important components that use structural ceramic materials. However, grinding of ceramics is difficult and more expensive due to the lower material removal rates (MRR). Cast iron-bonded diamond grinding wheels using ELID produce high material removal rates since the grain protrusion from the wheel size is maintained constantly using ELID. The results show that the normal grinding force is reduced when there is an increase of MRR using ELID grinding. The final surface roughness obtained from conventional and ELID grinding processes are 0.211 and $0.117 \mu \mathrm{m}$, respectively (Bandyopadyay et al 1996; Fujihara et al 1997; Bandyopadhyay \& Ohmori 1999; Bi Zhang et al 2000).

\subsection{Bearing steel}

The range of applications of cylindrical surfaces is wider in the manufacturing industry. Surface roughness and waviness are the two major factors, that affects the performance of rolling surfaces, because it induces noise and vibration of the components. Precision grinding of bearing steel was carried out using ELID and the surface finish, waviness and the roundness of the samples were compared with the conventional methods. The experiments were performed using both cast iron-bonded diamond wheels and CBN grinding wheels. The surface finish obtained using ELID showed an average surface roughness of $20 \mathrm{~nm}$ with \#4000 grinding wheel. Figure 8 shows the comparison of waviness obtained using different processes. From the comparison it is clear that the waviness of the surface obtained using ELID is smaller than the maximum allowable level (MAX) (Qian et al 2000). 


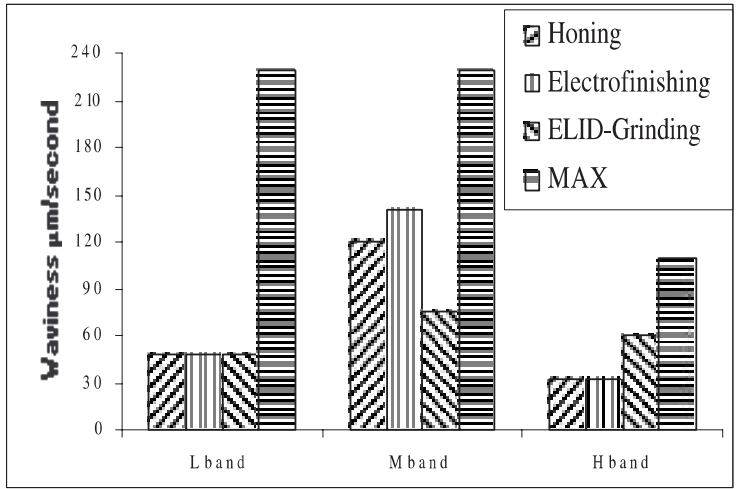

Figure 8. Comparison of waviness during different processes (Bi Zhang et al 2000).

\subsection{Chemical vapour deposited silicon carbide (CVD-SiC)}

The application of CVD-SiC has been increasing in recent years because of its excellent physical and optical properties. It is an ideal material for making reflection mirrors, but the finishing of this material is very difficult due to its hard and brittle nature. Nanosurface finish could be possible only when the material removal is done by a ductile mode. ELID grinding using cast iron-bonded diamond wheel of grit size \#4000 produced an average surface roughness of $7.2 \mathrm{~nm}$. Figure 9 shows the comparison of surface finish obtained using ELID and conventional methods at different grinding directions. The reason for better surface finish using ELID the thickness of the insulating layer, which acts as a damper during ELID (Zhanga et al 2001; Kato et al 2001).

\subsection{Precision internal grinding}

Precision cylindrical surfaces are widely used in the manufacturing industry. Finishing of internal cylindrical holes in a hard and brittle material becomes difficult because the accuracy and the tolerance mainly depend on the profile of the grinding wheel. The wheel profile should be perfect in order to get good tolerance. Cast iron fibre-bonded grinding wheels using the ELID-II method are highly suitable for internal grinding. The wheel profile is further improved by using electro discharge truing (EDT). Figure 10 shows the schematic diagram of internal

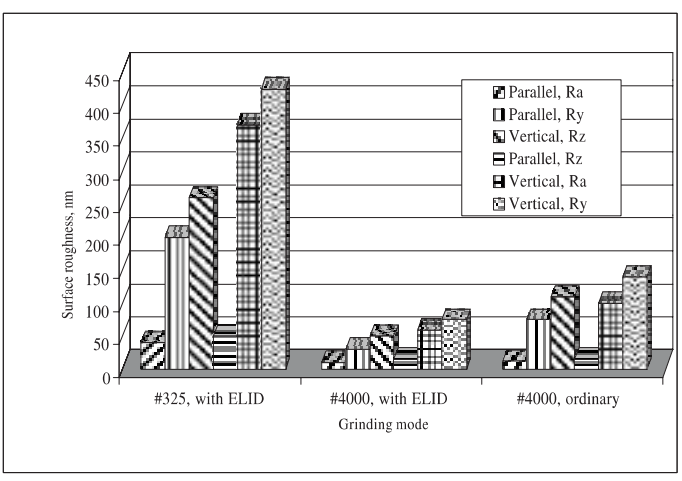

Figure 9. Comparison between different process for finishing CVD-SiC (Kato et al 2001; Zhanga et al 2001). 


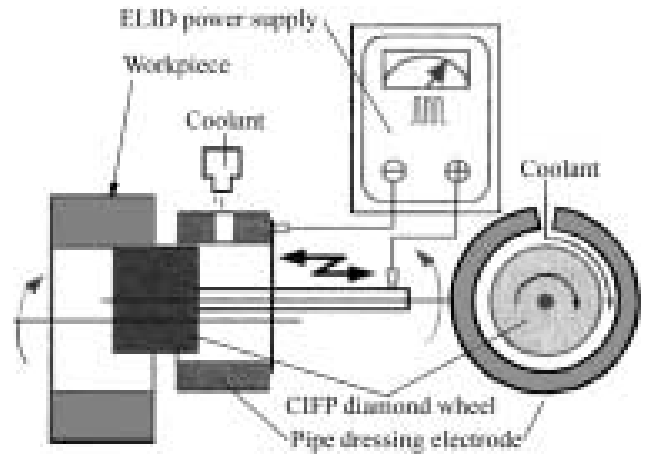

Figure 10. ELID-II using pipe electrode (Ohmori 1999).

hole grinding using interval dressing using pipe electrodes. Figure 11 shows the finished components and the surface finish obtained using the ELID-II technique (Ohmori et al 1999).

\subsection{Mirror surface finish on optical mirrors}

Finishing of larger X-ray mirrors is highly difficult using the conventional grinding processes. Superabrasive diamond grinding wheels and ELID are used to produce a mirror of $1 \mathrm{~m}$ length with an average surface finish of less than $10 \mathrm{~nm}$. It indicates that by using ELID grinding, high accuracy also can be obtained because roughing to finishing processes could be performed in the same machining setup (Zhang et al 2000; Wang et al 2000).

\subsection{Die materials}

Finishing of harder die materials such as SKDII and SKII51 with fine surface finish and accuracy is a great challenge in the manufacturing industry. The grinding ratio for such harder materials is lower, and the wheel wear rate increases significantly. ELID-IIIA technique has been implemented successfully for grinding of these kind of harder conductive materials. The workpiece is connected to the positive pole and the metal-resin bonded grinding wheel is connected to the negative pole. Electrolysis occurs between the workpiece and the grinding wheel, and a passive layer is formed on the workpiece surface, which reduces the effective depth of cut and improves the ground surface and the shape accuracy of the grinding wheel (Lim et al 2000, 2001).

(a)

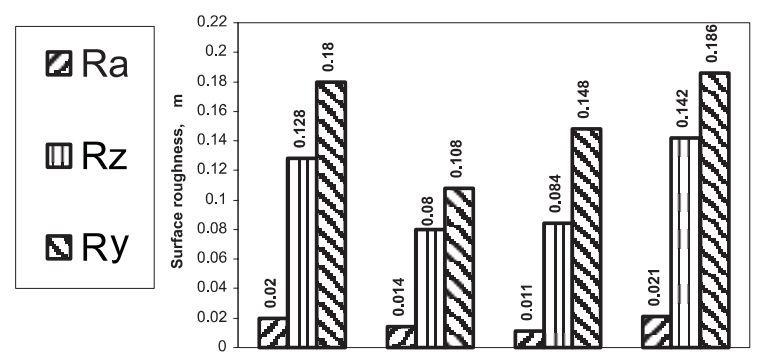

(b)

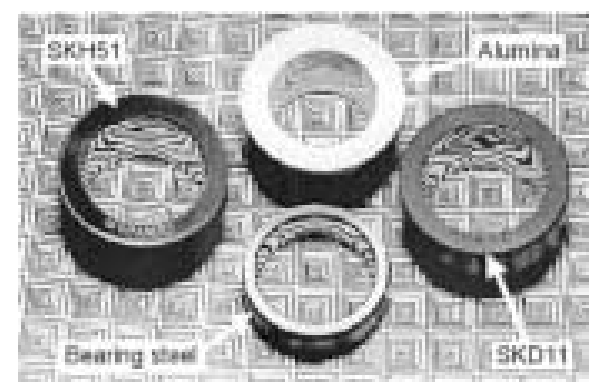

Figure 11. Precision internal grinding using ELID (Ohmori et al 1999). (a) Surface finish obtained; (b) finished components. 


\subsection{Precision grinding of $\mathrm{Ni}-\mathrm{Cr}-\mathrm{B}-\mathrm{Si}$ composite coating}

Surface coatings are necessary to prevent the material surface from wear and corrosion. Stephenson et al used CBN grinding wheels with the aid of ELID to finish the coated surface. They found that the surface finish using ELID shows limited damage to primary and secondary carbides. The surface ground without ELID shows damages in the form of carbide pullout and localized fracture due to the removal of large WC particles. The reason is ELID produces good protrusion of $\mathrm{CBN}$ grits that eliminates the carbide pullout. The ground surface measured shows an average surface roughness of 5-10 $\mathrm{nm}$ and $60-80 \mathrm{~nm}$ for with ELID and without ELID, respectively (Stephenson et al 2001; 2002).

\subsection{Micro-hole machining}

Machining of micro-holes in hard and brittle materials is a great challenge in manufacturing industries. Micro-holes of diameter $250 \mu \mathrm{m}$ were produced on ceramic materials. The micro-holes were produced using two types of grinding wheels such as cobalt-cast iron compound diamond grinding wheels and cast iron-bonded diamond grinding wheel. The grit sizes of the grinding wheels used in the experiments are \#325, \#500, and \#1200. Three different grinding fluids were also used to compare the efficiency of the grinding process.

The experimental results show that coolant selection also has a strong influence on the grinding forces. The proportion of oxide layer thickness and the etched layer thickness vary with the application of grinding fluid. Normally two kinds of electrodes such as arc and tube have been selected for interval dressing based on the grinding applications (Bandyopadhyay \& Ohmori 1999).

\subsection{ELID-lap grinding}

High flatness and mirror surface finish are the requirements in many industries nowadays. ELID-lap grinding is a constant pressure grinding which uses metal-bonded grinding wheels finer than \#8000. This method is highly efficient for grinding surfaces of different hardness at the same time. Experiments were conducted on two different materials such as silicon and cemented carbide. At first, the materials were ground separately and then ground together. The result shows that the surface finish is improved when they are ground together rather than ground separately. The finished workpiece that contains different materials is shown in figure 12 (Itoh et al 1998).

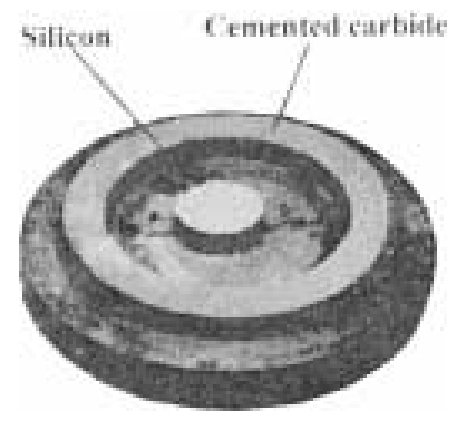

Figure 12. Component containing different materials finished using ELID-lap grinding (Itoh 1998). 


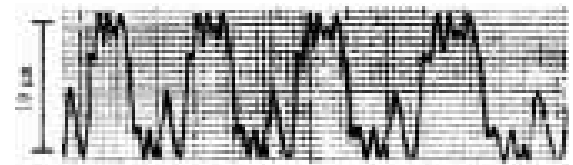

(a) As mounted (10jam,

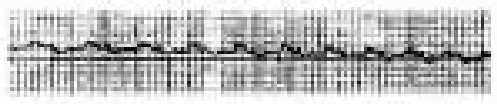

(b) After EDT $(1, \mu m$,
Figure 13. Profile of the grinding wheel before and after truing (Suzuki et al 1987).

\subsection{Grinding of silicon wafers}

Finishing of silicon wafers with nano accuracy and mirror surface finish is in great demand in the semiconductor industry. Grinding with superabrasive metal-bonded grinding wheels using ELID was found to be a good choice of producing mirror surface finish on silicon wafers (Ohmori \& Nakagawa 1990; Venkatesh et al 1995).

\section{Truing of grinding wheel}

Truing of metal-bonded grinding wheel is highly difficult due to its high bonding strength. Recent development of EDT shows good truing accuracy. A new rotating truing device is also developed for the purpose of truing metal-bonded grinding wheels (Uehara 2001).

Nagakawa (Suzuki et al 1997) introduced on-machine EDT that eliminates the difficulty of truing. In this method the grinding wheel can be trued after mounting on the machine spindle, which reduces the mounting errors and increases better truing accuracy. The grinding wheel profile obtained after truing using on-machine truing shows an accuracy of $3 \mu \mathrm{m}$ as shown in figure 13. Recent studies show that the combination of ELID and EDM process could be successfully used for nano-grinding, because the grinding wheel profile is corrected during grinding. The combined ELID and EDM setup is illustrated in figure 14 (Ohmori \& Lee 2000; Okuyama et al 2001).

\section{Fundamental studies on ELID grinding}

Different applications of ELID grinding were discussed in the previous section. Even though the studies show that the ELID process is highly suitable for producing nano-surface finish,

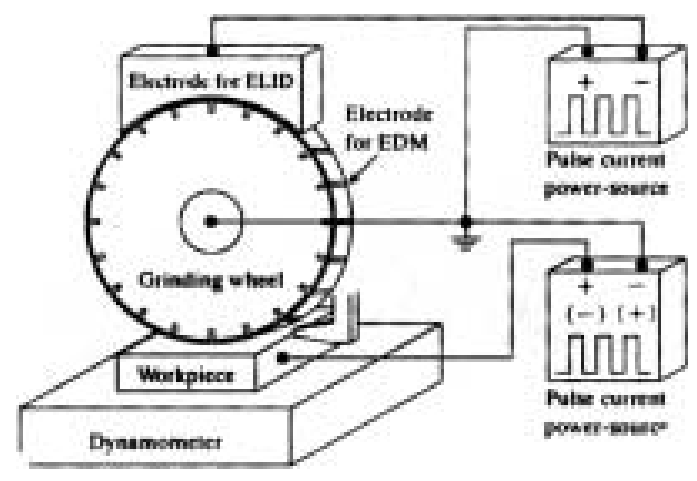

Figure 14. Combined ELID and EDM setup (Okuyama 2001). 


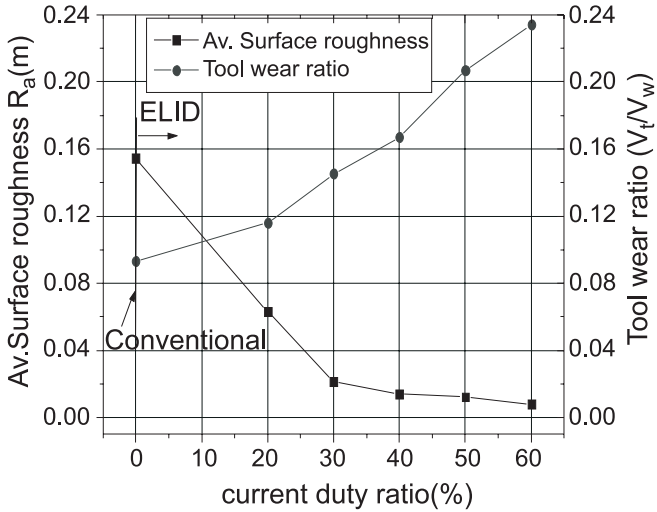

Figure 15. $R_{a}$ and wear ratio.

the fundamental studies about the process have not been not carried out. Some nonlinearities were found during in-process dressing due to the self-protecting oxide layer on the grinding wheel surface, resist the flow of current (Ohmori \& Nakagawa 1997). The thickness of the layer affects the ground surface finish and other parameters such as grinding force, grit protrusion and wheel profile. Lee (2000) studied the advantages of controlled ELID grinding by measuring the gap between the grinding wheel and the electrode. Controlled in-process dressing shows better results than uncontrolled dressing. The electrical parameters however are chosen to be the most influencing parameters during in-process dressing. Change in anyone of the electrical parameters affects the in-process dressing and the layer thickness. The authors conducted a fundamental study on the ELID grinding by suitably changing the electrical parameters in order to study the phenomena of the insulating layer formed on the grinding wheel surface and its influence on grinding parameters. This section explains the fundamental studies of the ELID grinding process.

Vertical grooves are ground on the surface of BK7 glass workpiece using different current duty ratios $\left(R_{c}\right)$. The current duty ratio is defined as the ratio between the current $\mathrm{ON}$ time of a cycle and the total time of a cycle as

$$
\text { current duty ratio }\left(R_{c}\right)=\{\text { ton } /(\text { ton }+ \text { toff })\} \times 100(\%) \text {, }
$$

where $t_{\mathrm{on}}$ is the ON time of a cycle and $t_{\text {off }}$ is its OFF time. Fundamental studies show the influence of change of current duty ratio on the oxide layer formation and the grinding parameters.

\subsection{Influence of in-process dressing conditions on surface roughness and tool wear}

This section discusses the influence of in-process dressing condition on surface roughness and tool wear. The surface roughness and tool wear ratio with respect to different current duty ratios are shown in figure 15. The tool wear ratio is defined as the reciprocal of the grinding ratio.

The average surface roughness $\left(R_{a}\right)$ and the tool wear ratio $\left(W_{t}\right)$ obtained from conventional grinding were $0.154 \mu \mathrm{m}$ and $0.093 \mu \mathrm{m}$ respectively. The $R_{a}$ and $W_{t}$ from ELID grinding process at $50 \%$ current duty ratio were found to be $0.0122 \mu \mathrm{m}$ and $0.207 \mu \mathrm{m}$ respectively. The average surface roughness improved more than 12 times and the tool wear ratio increased more than 2.23 times on applying the ELID grinding technique. Comparison between inprocess dressing at $50 \%$ and $60 \%$ current duty ratio shows the average surface roughness improved 1.5 times and tool wear ratio increased $13 \%$. 
(a)

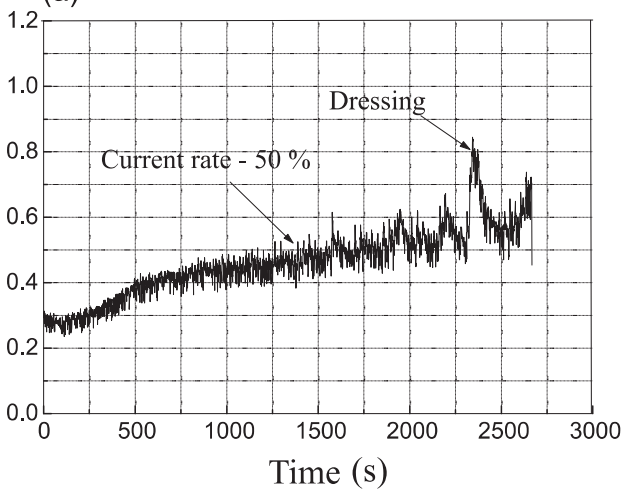

(b)

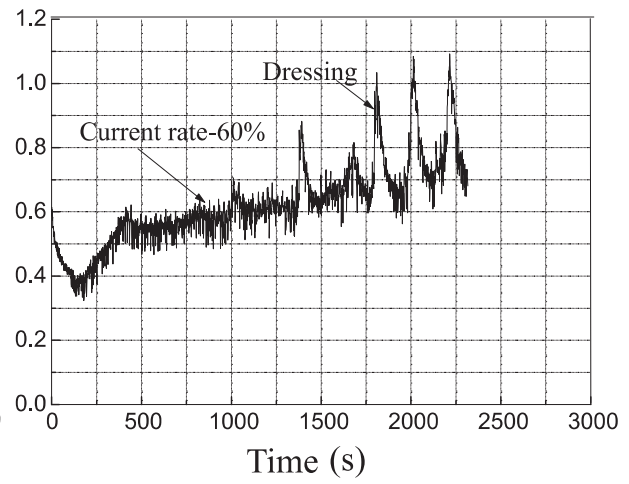

Figure 16. Dressing frequency at different $R_{c}$. Dressing current at 50\% (a) and 60\% (b) $R_{c}$.

The current recorded during in-process dressing at 50\% and $60 \%$ current duty ratios are shown in figure $16 \mathrm{a}$ and $\mathrm{b}$ respectively. From the comparison, it was found that at $60 \%$ duty ratio the dressing frequency was greater compared to that of the $50 \%$ duty ratio (Lim et al 2002).

The experiments show that the in-process dressing condition affects the surface roughness of the machined surface. The surface was assumed to have been ground by three types of grit. The first type of grit is tightly held by the bonding material and partially held by the oxide layer. The second type of grit is fully held by the oxide layer and the third type is worn diamond particles held by the layer. If the cutting pressure exceeds the holding pressure of a diamond grit, the worn diamond particles come out of the bonding matrix and become like loose abrasives and do the polishing (if the grit size is more than depth of cut). The grit held by the oxide layer is loosely held in the bond and the process is the same as the lapping process. The oxide layer holding the diamond grit is like the lapping pad and the bonding material acts like a supporting pad. The grit that is held tightly by the bonding material does the real grinding. Thus, during ELID, a smoother surface can be obtained. When the thickness of the oxide layer increases, the abrasives are loosely bonded and the grinding process becomes almost like a polishing process. From the experiments, it is observed that the surface roughness is much better when the current duty ratio increases. The oxide layer formed on the grinding wheel surface acts as a damper and minimizes grinding chatter. The rigidity of the machine is also important to get a fine surface finish.

However, ELID minimizes machine stability problems because the oxide layer formed on the surface of the wheel improves the quality of the protrusion height of the grain cutting edge and mirror surface finish is possible with low rigidity machines. If the grinding wheel is dressed more frequently, the work surface is always ground with freshly protruded diamond particles, which can produce smoother surfaces. The disadvantage of using high current duty ratio is that excessive tool wear is observed and hence the grinding wheel is dressed more often (Shimada et al 1995).

\subsection{Grinding modes and ELID techniques}

Figures 17a-c show the Nomarski interference microscopic (OLYMPUS) observations of ground glass surfaces machined at a spindle speed of $3000 \mathrm{rpm}$, feed rate of $200 \mathrm{~mm} / \mathrm{min}$, depth of cut of $1 \mu \mathrm{m} /$ pass and $50 \%$ current duty ratio with three different grinding wheels of 
(a)

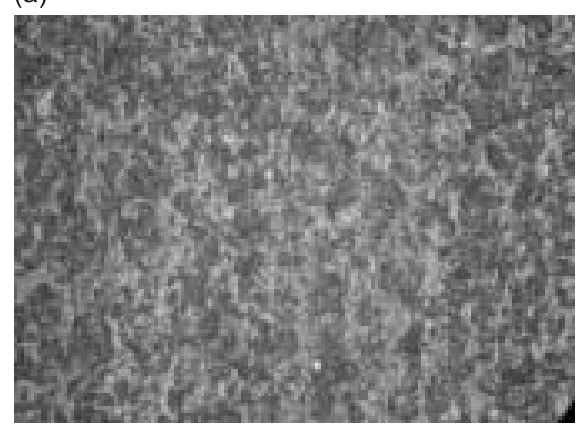

(c)

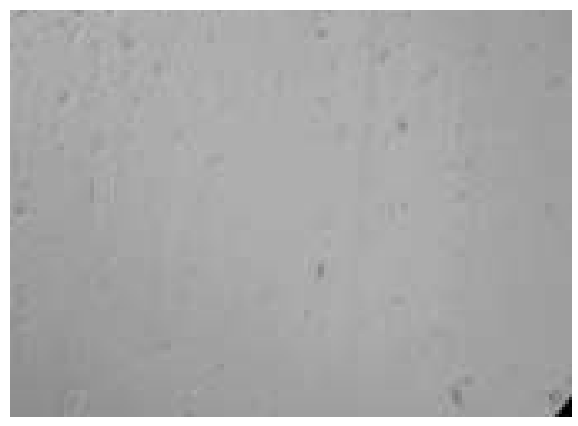

(e)

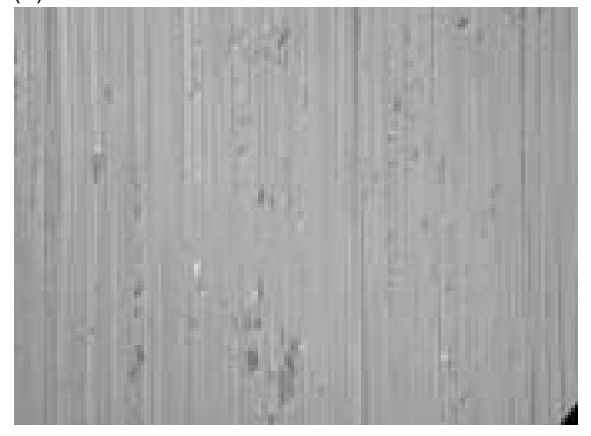

(b)

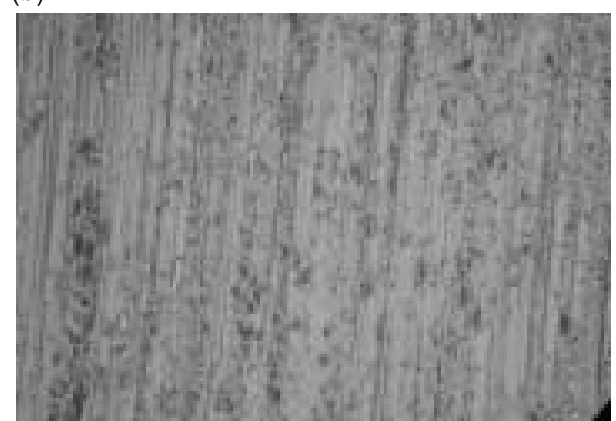

(d)

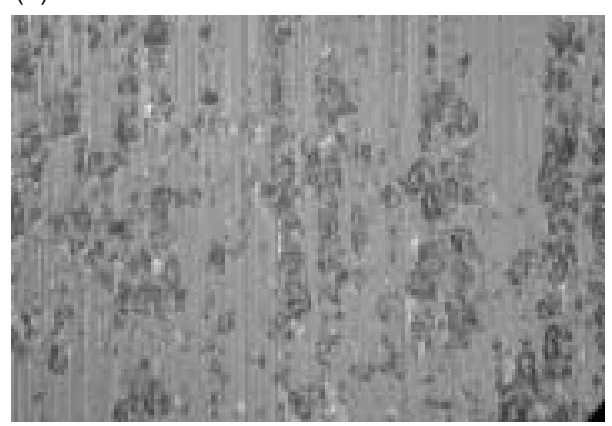

Figure 17. Nomarski microscopic image of three different grinding modes obtained by using different grade grinding wheels on glass! (a) brittle mode (\#325); (b) brittle to ductile transition mode (\#1200); (c) ductile mode (\#4000). Nomarski microscopic image of ground glass surfaces using \#1200 grade wheel using (d) conventional and (e) ELID technique. (a)

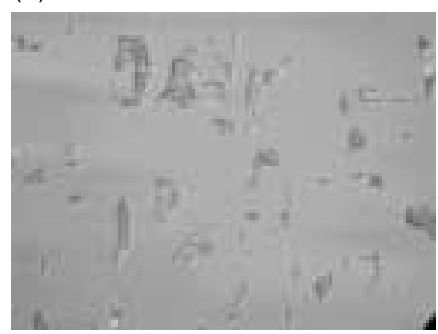

(b)

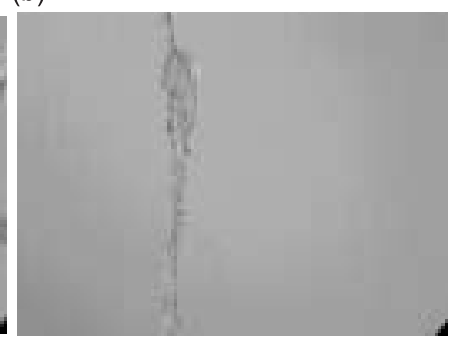

(c)

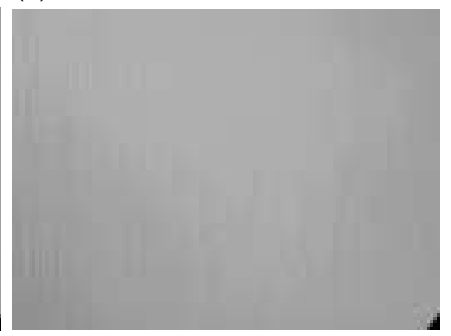

Figure 18. Nomarski microscopic images of ground surfaces at different current duty ratios. (a) Surface damage $\left(R_{c}-20 \%\right)$; (b) surface crack $\left(R_{c}-40 \%\right)$; (c) defect free surface $\left(R_{c}-50 \%\right)$. 
grades \#325, \#1200 and \#4000 using an ELID grinding technique. The grit sizes of grinding wheels are $40 / 60 \mu \mathrm{m}, 8 / 20 \mu \mathrm{m}$ and $2 / 6 \mu \mathrm{m}$ for the above grade wheels respectively. The surface roughness of the ground surfaces was measured using Form Talysurf (Tailor-Hobson) with a stylus of diameter $2 \mu \mathrm{m}$. A glass surface ground (figure 18) using a \#325 grit size wheel produces a complete fracture mode surface of $R$ (average roughness) $=0.5629 \mu \mathrm{m}$. The observed surface is cloudy due to the brittle mode machining. The second surface machined with \#1200 wheel is partially transparent and this is due to the brittle to ductile transition mode of $R=0.1614 \mu \mathrm{m}$. The third surface shows a complete transparent surface with a full ductile mode of $R=0.0604 \mu \mathrm{m}$ which was machined using \#4000 wheel. Figures $17 \mathrm{~d}$ and e show the Nomarski microscopic image of the ground surfaces machined using \#1200 grade wheel with and without the application of the ELID grinding technique. The ground surface obtained using the ELID grinding technique contains less crashed parts (produced due to the interruption of grinding steaks) than that without ELID. The average surface roughness of the ground surfaces with and without the application of ELID technique was found to be $0 \cdot 1491 \mu \mathrm{m}$ and $0 \cdot 3795 \mu \mathrm{m}$ respectively.

The ground surfaces were examined under a Nomarski microscope both for grinding mode classification and for identification of surface defects. All the ground surfaces observed are under the condition of ductile mode. Figure 18a shows that the surface contains pits at $20 \%$ current duty ratio. The surface ground using 30 and $40 \%$ current duty ratios contains micro cracks, while the surfaces ground using current duty ratio of $50 \%$ and above show defect-free ductile surfaces (figures $18 \mathrm{~b}$ and $\mathrm{c}$ ).

The grinding mode of the ground glass surface is influenced by the grit size of the wheel that has very little or no influence on the machining and pre-dressing conditions. It is found that the application of the ELID technique improves the surface roughness of the ground surface. The active sharp grits per unit area of the grinding wheel slowly start decreasing during the conventional grinding process. In the case of the ELID grinding technique, the active sharp grits per unit area of the wheel remain almost constant at better dressing conditions and this leads to improved surface integrity and surface roughness. The metal-bonded diamond

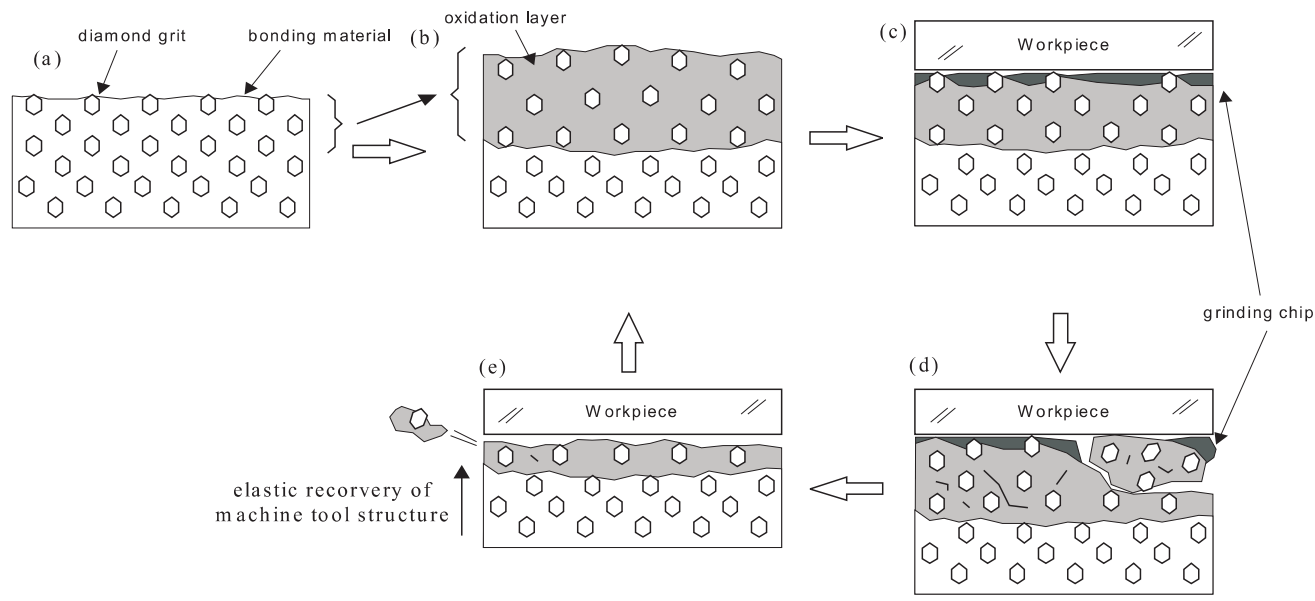

Figure 19. Change of wheel surface during ELID grinding (a) after truing, (b) growing of oxidation layer by dressing current, (c) compression and wheel loading, (d) end of breakage cycle, (e) crack propagation and start breakage. 
grinding wheels have better grindability and stiffness. However, the wheel-working surface is harder because of high bonding strength. The bonding strength of the wheel-working surface should be reduced for better grinding results. An efficient way of reducing the bonding strength is using the electrolytic dressing process.

Even though electrolytic dressing reduces the strength of the bonding material, the layer has enough strength to hold the diamond grits during grinding. Figure 19 shows the change of wheel surface while grinding. If the cutting pressure exceeds a certain value, which depends on the machining conditions, the layer starts breaking. The outer layer contains worn grits and grinding chips are removed along with the layer. The new layer of the grinding wheel beneath the broken layer contains fresh diamond grits that come into cutting action. The new layer is softened by electrolysis and the speed of the electrolysis depends on the duty ratio of the dressing current. If the grit height reduces due to grit wear, the oxide layer contacts the workpiece, which then leads to crack propagation, as shown in figure 19. The complete layer is removed due to the hardness of the workpiece.

The breakage of the outer insulating layer increases the electro-conductivity of the grinding wheel, which stimulates electrolysis, causing an increase in dressing current and reducing the normal cutting force. The sudden increase in tangential force is also because of the removal of the outer insulating layer from the grinding wheel. This cycle repeats throughout the grinding process and forms periodic patterns on the normal force diagram.

For equal volume of stock removal, the grinding ratio reduces with the increase in current duty ratio. The reduction of grinding ratio for the same material removal rate implies that the wheel wear is larger at higher current duty ratios. If the layer is soft, the breakage of oxide layer is larger, and this leads to more wheel wear for the same amount of material removal. Hence, it can be concluded that the oxide layer produced at high current duty ratios is softer than that produced at low current duty ratio. If the oxide layer is hard, the worn grains are tightly held on the bonding matrix. After a definite interval, the grinding wheel surface contains more worn grains and the material removal is done only by the rubbing action. The rubbing action increases the damage of the work surface due to the increase in grinding temperature.

The hardness and the topography of the wheel-working surface influence the ground glass surface. At 50\% and more current duty ratios, the wheel-working surface is softer and can retain almost a constant grit number in action so that the load per grit is reduced. The grinding wheel profile is improved with the increase of grinding time with the application of ELID grinding. From the above studies it is concluded that the in-process dressing affects the grinding mode. Ductile mode grinding could be possible when the current duty ratio of $40 \%$ and more have been selected (Shimada et al 1995; Kumar et al 2002).

\section{Concluding remarks}

Study of ELID grinding shows that it is highly suitable for achieving nano-surface finishes on metals and non-metals. Different types of ELID process are highly suitable for machining and finishing micro shapes. Nano-surface finish can be achieved by using ductile mode machining on hard and brittle materials. The results show that the ELID grinding can produce ductile surfaces without any sub-surface damage, which eliminates the lapping and polishing processes. Thus, surface finish can be improved with higher accuracy and tolerance since the component is produced using only one process. The major difficulties are the lack of feedback devices to control the in-process dressing, optimization of machining conditions and modelling of ductile mode grinding. 
The authors would like to thank Dr H Ohmori and his ELID team at RIKEN, Japan for their assistance.

\section{References}

Bandyopadhyay B P, Ohmori H 1999 The effect of ELID grinding on the flexural strength of silicon nitride. Int. J. Machine Tools Manuf. 39: 839-853

Bandyopadhyay B P, Ohmori H, Takahashi I 1996 Ductile regime mirror finish grinding of ceramics with electrolytic in-process dressing (ELID) grinding. Mater. Manuf. Proc. 11: 789-801

Fujihara K, Ohshiba K, Komatsu T, Ueno M, Ohmori H, Bandyopadhyay B P 1997 Precision surface grinding characteristics of ceramic matrix composites and structural ceramics with electrolytic inprocess dressing. Machining Sci. Technol. 1: 81-94

Itoh N, Ohmori H, Moriyasu S, Kasai T, Toshiro K, Bandyopadhyay B P July 1998 Finishing characteristics of brittle materials by ELID-lap grinding using metal-resin bonded wheels. Int. J. Machine Tools Manu. 38: 747-762

Kato T, Ohmori H, Zhang C, Yamazaki T, Akune Y, Hokkirigawa K 2001 Improvement of friction and wear properties of CVD-SiC films with new surface finishing method 'ELID-grinding' Key Eng. Mater. 196: 91-101

Kumar A S, Lim H S, Rahman M, Fathima K 2002 A study on grinding of glass using electrolytic in-process dressing (ELID) grinding. J. Electron. Mater. 31: 1039-1046

Lee E S 2000 A study of the development of an ultraprecision grinding system for mirror-like grinding, Int. J. Adv. Manuf. Technol. 16: 1-9

Lim H S, Ohmori H, Lin W, Qian J 2000 High productivity and high accuracy electrode-less ELID grinding on die material. J. Mould Tehcnol. 15: 148-149 (in Japanese)

Lim H S, Ohmori H, Lin W, Qian J 2001 Electrode-less micro ELID grinding on die and mould material. J. Soc. Grinding Eng. 45: 298-303

Lim H S, Fathima K, Kumar A S and Rahman M 2002 A fundamental study on the mechanism of electrolytic in-process dressing (ELID) grinding. Int. J. Machine Tools Manuf. 42: 935-943

Murata R, Okano K, Tsutsumi C 1985 Grinding of structural ceramics. Milton C Shaw Grinding Symposium PED 16: 261-272

Ohmori H, Nakagawa T 1990 Mirror surface grinding of silicon wafers with electrolytic in-process dressing. Ann. CIRP 39/1: 329-333

Ohmori H, Nakagawa T 1995 Analysis of mirror surface generation of hard and brittle materials by ELID (electronic in-process dressing) grinding with superfine grain metallic bond wheels. CIRP Ann.-Manuf. Technol. 44: 287-290

Ohmori H, Nakagawa 1997 Utilization of nonlinear conditions in precision grinding with ELID (electrolytic in-process dressing) for fabrication of hard material components. CIRP Ann. Manuf. Technol. 46: 261-264

Ohmori H, Qian J 2000 ELID-II grinding of micro spherical lens. RIKEN Rev. 23: 140

Ohmori H, Moriyasu S, Li W, Takahashi I, Park KY, Itoh N, Bandyopadhyay B P 1999 Highly efficient and precision fabrication of cylindrical parts from hard materials with the application of ELID (electrolytic in-process dressing). Mater. Manuf. Proc. 14: 1-12

Ohmori H, Li W, Makinouchi A, Bandyopadhyay B P 2000 Efficient and precision grinding of small hard and brittle cylindrical parts by the centerless grinding process combined with electro-discharge truing and electrolytic in-process dressing. J. Mater. Proc. Technol. 98: 322-327

Okuyama S, Yonago M, Kitajima T, Suzuki H 2001 A basic study on the combination machining of ELID-grinding and EDM-experiments of combination machining using a pulse power-source. $J$. Jpn. Soc. Precision Eng. 67: 407-412

Qian J, Wei L, Ohmori H 2000 Cylindrical grinding of bearing steel with electrolytic in-process dressing. Precision Eng. 24: 153-159

Qian J, Ohmori H, Lin W 2001 Internal mirror grinding with a metal/metal-resin bonded abrasive wheel. Int. J. Machine Tools Manuf. 41: 193-208 
Shimada S, Ikawa N, Inamura T, Takezawa N, Ohmori H, Sata T 1995 Brittle-ductile transition phenomena in microindentation and micromachining. CIRP Ann. - Manuf. Technol. 44: 523-526

Stephenson D J, Veselovac D, Manley S, Corbett C 2001 Ultra-precision grinding of hard steels. Precision Eng. 25: 336-345

Stephenson D J, Hedge J, Corbett J 2002 Surface finishing of Ni-Cr-B-Si composite coatings by precision grinding. Int. J. Machine Tools Manuf. 42: 357-363

Suzuki K, Uematsu T, Nakagawa T 1987 On-machine truing/dressing of metal-bonded grinding wheels by electro-discharge machining. CIRP Ann. 36: 115-118

Uehara Y, Ohmori H, Yamagata Y, Moriuasu S, Makinouchi A, Morita S 2001 Microfabrication grinding by ultraprecision microform generating machine employed with plasma discharge truing and ELID technique RIKEN Rev. 34: 25-28

Venkatesh V C, Inasaki I, Toenshof H K, Nakagawa T, Marinescu I D 1995 Observations on polishing and ultraprecision machining of semiconductor substrate materials. CIRP Ann. - Manuf. Technol. 44: 611-618

Wang P, Shi Z, Xin Q 2000 Optical surface grinding of optical glasses with ELID grinding technique. Proc SPIE - Int. Soc. Opt. Eng. 4231: 509-514

Zhang F, Li W, Qiu Z, Ohmori H 2000 Application of ELID grinding technique to precision machining of optics. Proc. SPIE - Int. Soc. Opt. Eng. 4231: 218-223

Zhanga C, Ohmori H, Kato T, Morita N 2001 Evaluation of surface characteristics of ground CVD$\mathrm{SiC}$ using cast iron bond diamond wheels. Precision Eng. 25: 56-62

Zhang Bi, Yang F, Wang J, Zhu Z, Monahan R 2000 Stock removal rate and workpiece strength in multi-pass grinding of ceramics. J. Mater. Process. Technol. 104: 178-184

Zhang C, Ohmori H, Li W 2000 Small-hole machining of ceramic material with electrolytic intervaldressing (ELID-II) grinding. J. Mater. Process. Technol. 105: 284-293 